\title{
Childhood neurodegeneration associated with a specific UBTF variant: a new case report and review of the literature
}

\author{
Filipa Bastos ${ }^{1,2^{*}}$ (D), Mathieu Quinodoz ${ }^{3}$, Marie-Claude Addor ${ }^{4}$, Beryl Royer-Bertrand ${ }^{3,4}$, Heidi Fodstad ${ }^{4}$, \\ Carlo Rivolta ${ }^{3,5}$, Claudia Poloni ${ }^{1,6}$, Andrea Superti-Furga $^{4}$, Eliane Roulet-Perez ${ }^{1}$ and Sebastien Lebon ${ }^{1}$
}

\begin{abstract}
Background: A new monogenic neurodegenerative disease affecting ribosomal metabolism has recently been identified in association with a monoallelic UBTF putative gain of function variant (NM_001076683.1:c.628G>A, hg19). Phenotype is consistent among these probands with progressive motor, cognitive, and behavioural regression in early to middle childhood.

Case presentation: We report on a child with this monoallelic UBTF variant who presented with progressive disease including regression, episodes of subacute deterioration during febrile illnesses and a remarkable EEG pattern with a transient pattern of semi-periodic slow waves.

Conclusions: This case further supports the phenotype-genotype correlation of neurodegeneration associated with UBTF c.628G >A. Moreover, it brings new insights into the clinical features and EEG that could possibly serve as diagnostic markers of this otherwise nonspecific phenotype.
\end{abstract}

Keywords: Neurodegeneration, UBTF, EEG

\section{Background}

Recently three independent teams [1-3] reported on a new monogenic neurodegenerative disease of childhood associated with a specific monoallelic de novo c.628G>A (p.Glu210Lys) UBTF variant. Together, 12 male and female patients aged 6 to 33 years old were described with a consistent phenotype of normal or close to normal early developmental milestones followed by motor and cognitive regression [1-3].

UBTF (Upstream Binding Transcription Factor, OMIM *600673) gene codes for Upstream Binding Factor (UBF), a protein that acts as a transcription factor for RNA polymerase I, essential for the generation of ribosomal RNA transcripts (rRNA) from ribosomal DNA (rDNA) in the nucleolus $[1,2]$. The c.628G $>A$ variant

\footnotetext{
* Correspondence: Filipa.Bastos-Bettencourt@chuv.ch

'Department woman-mother-child, Unit of Paediatric Neurology and Neurorehabilitation, Lausanne University Hospital (CHUV), Rue du Bugnon 21, 1011 Lausanne, Switzerland

${ }^{2}$ Great Ormond Street Hospital Institute of Child Health, University College London, 30 Guilford Steet, London WC1N 1EH, United Kingdom

Full list of author information is available at the end of the article
}

confers a gain of function to the protein resulting in increased expression of rDNA and rRNA, which in turn is thought to lead to scavenging of RNA binding proteins, altered RNA disposal machinery and ribosome biogenesis [1], as well as defective DNA damage repair and chromatid cohesion $[1,2,4,5]$.

We describe a further case of childhood neurodegeneration associated with this $U B T F$ variant and add new insights on clinical evolution and electro-encephalographic features.

\section{Case presentation}

This 12-year-old boy was referred at 5 years of age for developmental delay (Fig. 1). He was the first child of unrelated sri-lankan parents; two younger siblings were healthy. His medical history was unremarkable and developmental milestones were normal up to 2 years of age, when parents noted speech and expressive language difficulties, frequent falls, and slowing of developmental progress without plateauing or loss of skills. At presentation, head circumference was at $10-25^{\text {th }}$ 


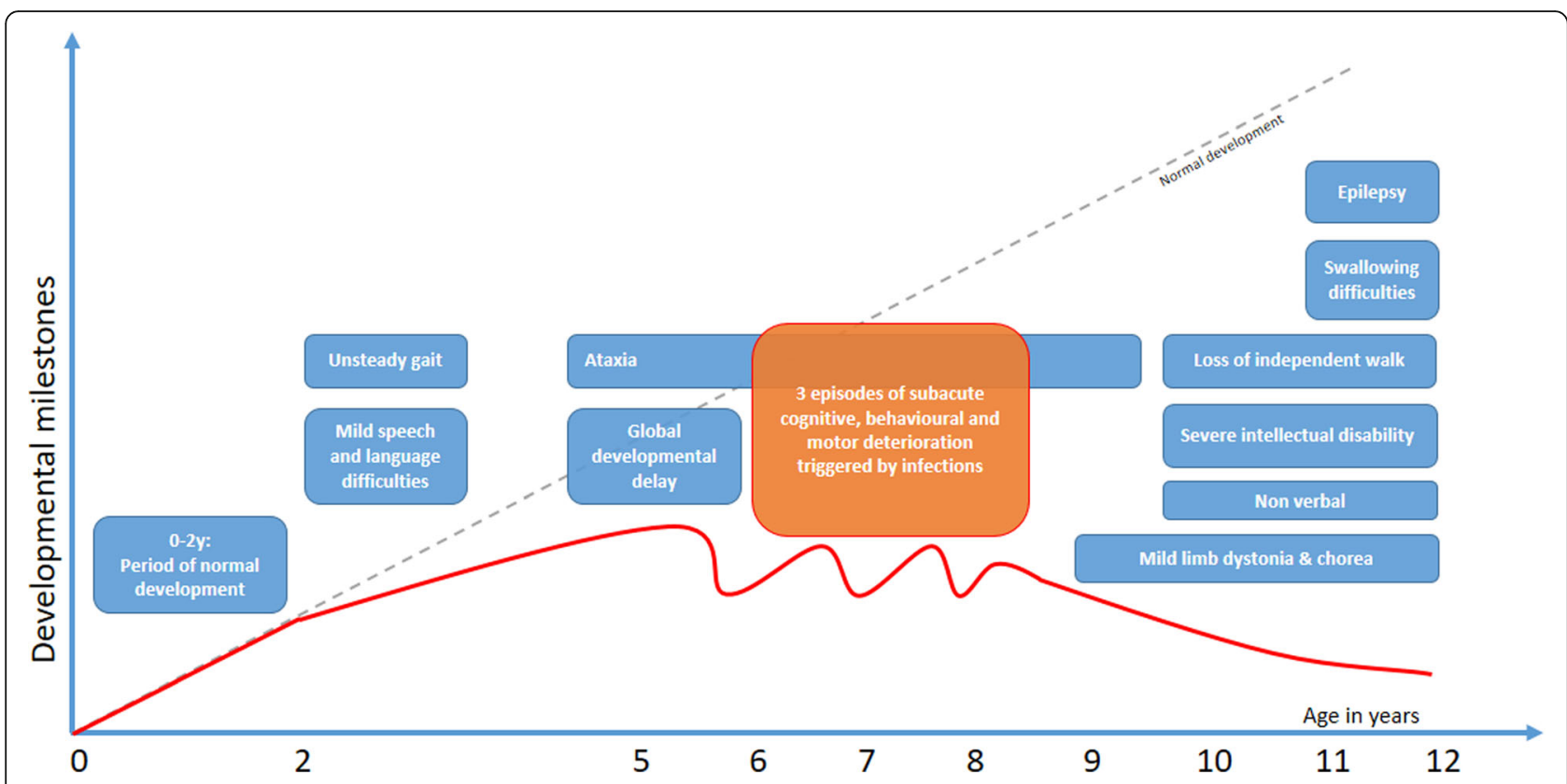

Fig. 1 Time course of the disease. Diagram illustrating time course of disease in our patient. Dotted grey line: normal developmental trajectory; Red Line: developmental trajectory in our patient; Blue boxes: main signs and symptoms; Orange box: highlights period of subacute deterioration possibly triggered by infection

centile, height at $75-90^{\text {th }}$ and weight at $25^{\text {th }}$. On clinical examination, organomegaly or dysmorphic signs were absent. There was mild hypotonia with ataxia of limbs and gait ; cranial nerves and deep tendon reflexes (DTR) were normal. Development was globally delayed. Ten months later, following a febrile illness, the boy presented with alternating periods of agitation and apathy, loss of sphincter control, expressive and receptive language regression and worsening of the cerebellar syndrome. Three similar episodes occurred between age 6 and 8 years, all triggered by benign infectious illnesses. Thereafter, he displayed a downhill course with progressive deterioration. At the age of 11 years he developed brief epileptic behaviour arrests. At 12 years old, he has a severe intellectual disability (ID) and is nonverbal but retains a friendly behaviour. He is unable to walk unassisted and has swallowing difficulties. He has a cerebellar syndrome with mild limb dystonia and choreic movements, brisk DTR without other pyramidal signs.

A first brain magnetic resonance imaging (MRI) done at 5 yo, prior to regression, showed mild white matter atrophy and periventricular hyperintensities on T2-weighted (T2W) images (Fig. 2). Follow-up MRIs done at age 6, 7 and 9 years showed progressive cortico-subcortical supratentorial atrophy, periventricular and peritrigonal deep white matter T2 hyperintensities (Fig. 2) with an increased apparent diffusion coefficient. Cerebellum appeared mildly atrophic at 9 yo.
A first electroencephalogram (EEG) done at 5 yo (Fig. 3a) showed bilateral fronto-central spike and spike-wave (SW) complexes during drowsiness and sleep stage I with slightly slow background rhythm for age $(7-8 \mathrm{~Hz})$. From 7 to 9 yo, 2 EEGs showed a pattern of semi-periodic diffuse slow delta waves complexes occurring every 2 to 5 seconds (0.2$0.3 \mathrm{~Hz}$ ) during wakefulness without clinical correlate (Fig. 3b). Sleep EEG kept on showing frequent anterior spike and SW complexes that became diffuse from 9 yo (Fig. 3c). Electroclinical seizures were recorded at 11 yo, with diffuse alpha rhythmic discharges at $11 \mathrm{~Hz}$ during 10 seconds correlating with behavioural arrest. Photosensitivity was never elicited (minimum frequency $1 \mathrm{~Hz}$ ). Visual and auditory evoked potentials were normal.

A first cerebral-spinal fluid (CSF) analysis during the first episode of regression at age 6 years showed 5 lymphocytes $/ \mathrm{mm}^{3}$ and normal lactate, glucose and proteins levels. Two subsequent spinal taps at age 7 years were normal. Extensive workup including ammonium, lactate, organic acids, amino-acids, acylcarnitines profile, lysosomal enzymes activities, anti-neuronal antibodies (CSF and serum), anti-measles and anti-rubella antibodies (serum and CSF), prion and interferon signature were all negative.

At first, an Array Comparative Genomics Hybridisation (Agilent oligoNT array CGH 180K) was undertaken and did not reveal any pathogenic change. Whole Exome 


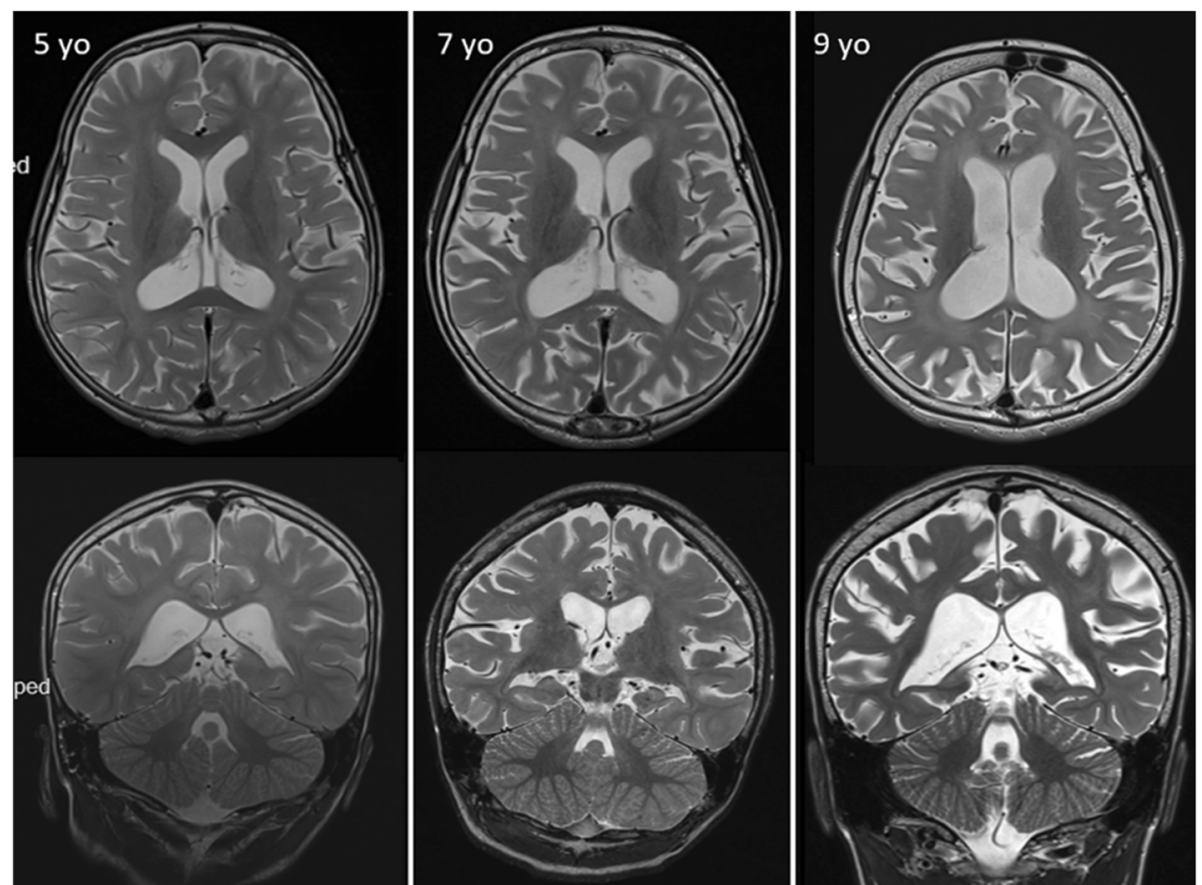

Fig. 2 Brain MRI of the patient at different ages. Axial and coronal T2-weighted images. Supratentorial progressive cortical and subcortical atrophy with ex vacuo ventriculomegaly and diffuse deep white matter hyperintensities. Note that MRI is already abnormal at 5yo, before onset of regression. Cerebellar atrophy is only marginal. Basal ganglia, U-fibres, optic radiations, internal capsule and hippocampi were globally preserved

Sequencing was then performed on Illumina HiSeq2500 sequencer, with Agilent Sure Select XT Human All Exon V5 capture kit, after appropriate informed consent. The raw data from Whole Exome Sequencing (WES) were screened using an in-house pipeline as previously described [6] allowing for filtering of synonymous and common variants to which a panel of approximately 1300 genes known to be implicated in developmental delay and seizure disorders was applied. The original analysis failed to yield any variant that might be plausibly linked to an intellectual disability or epilepsy phenotype [7]. The data were reanalyzed six months later using an updated panel that (at that point) contained the gene $U B T F$, that had just been published in connection with an intellectual disability phenotype by Edvardson et al [1]. This allowed for the detection of a heterozygous c.628G $>$ A UBTF variant, which was confirmed by Sanger sequencing and found to be de novo.

\section{Literature Review}

The literature search yielded two case series and a case report of patients carrying the same de novo heterozygous c.628G $>$ A $U B T F$ variant [1-3]. Results are summarised in Table 1. Median age of onset of regression was 3 yo after a period of normal development for 10 patients. Early signs include gait ataxia, hypotonia, speech and language difficulties and behavioural and cognitive disorders. Most patients developped extrapyramidal and pyramidal signs. By early teen age, all individuals have severe ID, loss of ambulation and autonomy. No extra-central nervous system manifestations were described so far. Although EEG is abnormal in half the patients, epilepsy affected only one third of the patients, and was reported as severe in only one case [3]. Brain MRI shows predominant supratentorial atrophy and T2 deep white matter hyperintensities. Cerebellar atrophy is less remarkable but reported in the majority of cases.

\section{Discussion and Conclusions}

After 5 years of diagnostic wandering, the finding of the specific, monoallelic de novo mutation c.628G >A (p.Glu210Lys) in UBTF allowed us to recognise a newly-described neurodegenerative disease characterized by motor, behavioural, and cognitive regression in early childhood.

Although the phenotype is nonspecific, it is in line with the previous reported cases: regression begins in pre-school years (median age 3 years) and is followed by global neurological deterioration progressing until the beginning of the second decade. Involvement is confined to the central nervous system. Speech, language and motor delay can be present prior to regression. Cognitive and behavioural degradation follows no specific 


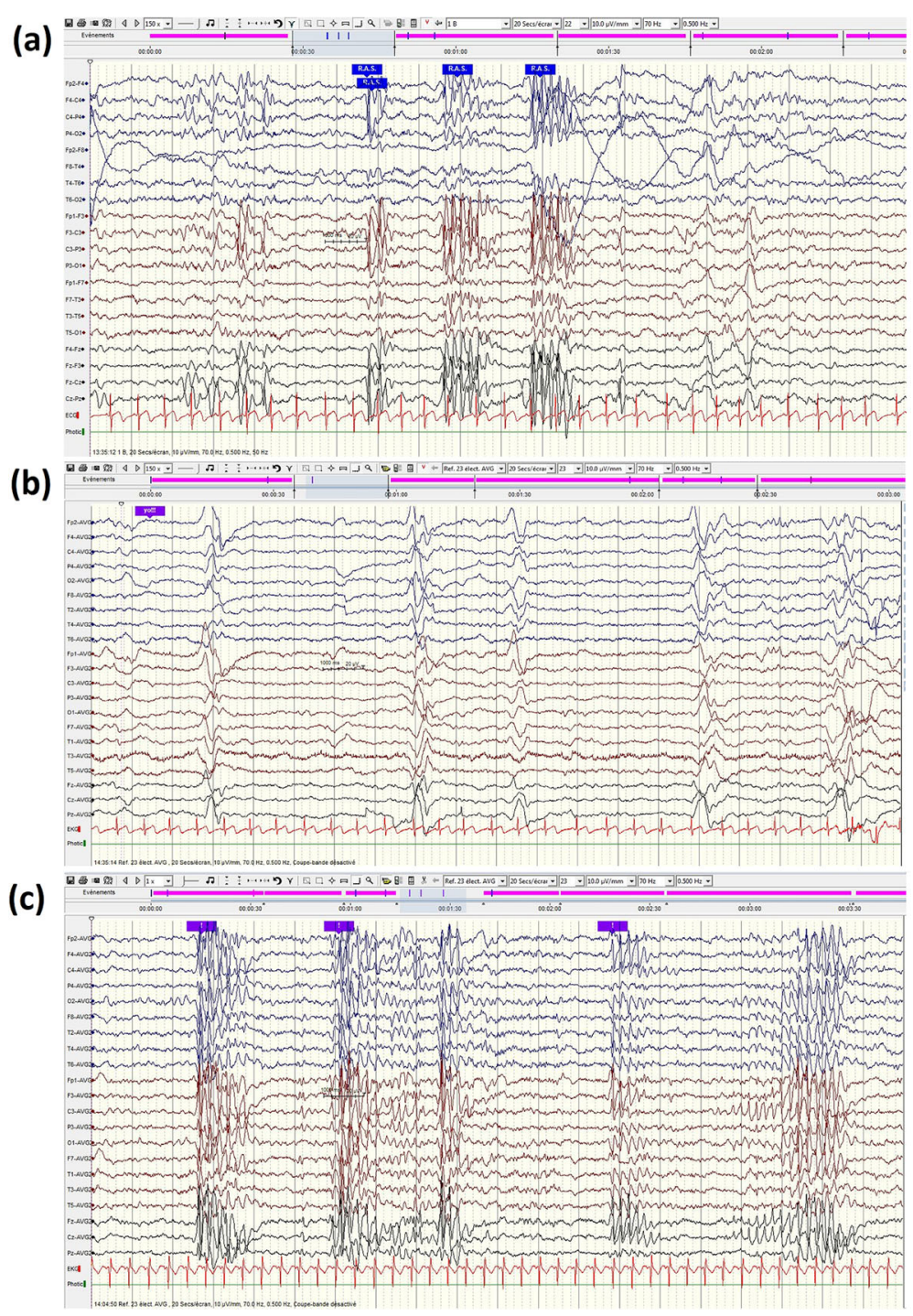

Fig. $3 \mathrm{EEG}$ of the patient at different ages. a 5 yo, during drowsiness bilateral bursts of frontocentral spike-wave complexes, without clinical correlate (b) 7yo, semi periodic delta waves without clinical manifestation; (c) 9yo, generalized spikes ad spike-waves complexes without clinical correlation (during sleep). Background wake activity max 7-8Hz on a,b and c

pattern. Autistic traits and aggressiveness were described but absent in our case. Most patients develop cerebellar, pyramidal, extrapyramidal signs and microcephaly overtime. MRI findings are also consistent, showing cortico sub cortical atrophy with T2 hypersignal involving white matter and sometimes basal ganglia. Of note, despite a high incidence of extrapyramidal signs, basal ganglia are rarely abnormal.

Our case adds new insights on the natural history and EEG features of these patients. First, phases of neurological deterioration coincided with febrile and afebrile infectious illnesses and were followed by incomplete recovery. This finding was reported in only one other case [3] but could have been underreported. In both patients, it occurred in the first stage of the disease. Fever and infection-triggered regression is known in metabolic diseases such as mitochondrial diseases or organic acidurias [8], but also in white matter disorders such as vanishing white matter [9] for which we found no evidence. Here, fever-induced metabolic stress may have worsened the disease course because the UBF protein has a major role in rDNA transcription, and thus in ribosomal biogenesis, which is a highly energy consuming process essential for cell integrity [10]. Second, the EEG evolution was remarkable. As in others neurodegenerative disorders, there was a progressive and nonspecific slowdown of background activity. But, after the regression, we found twice, at 7 and 8 years, a peculiar pattern of generalized semi-periodic slow waves $(0.2-0.3 \mathrm{~Hz})$ without 
Table 1 Phenotype of patients with the UBTF c.628G>A variant

\begin{tabular}{|c|c|c|c|c|c|}
\hline & $\begin{array}{l}\text { Edvardson et al [1] } \\
N=7\end{array}$ & $\begin{array}{l}\text { Toro et al [2] } \\
\mathrm{N}=4\end{array}$ & $\begin{array}{l}\text { Sedlackova et al [3] } \\
N=1\end{array}$ & $\begin{array}{l}\text { Present study } \\
\mathrm{N}=1\end{array}$ & $\begin{array}{l}\text { Total } \\
\mathrm{N}=13\end{array}$ \\
\hline Gender & $1 \mathrm{M} / 6 \mathrm{~F}$ & $2 \mathrm{M} / 2 \mathrm{~F}$ & $1 \mathrm{M}$ & $1 \mathrm{M}$ & $5 \mathrm{M} / 8 \mathrm{~F}$ \\
\hline $\begin{array}{l}\text { Age at } \\
\text { publication, yo } \\
\text { (median, } \\
\text { interval) }\end{array}$ & $17[8-23]$ & $12[6-33]$ & 13 & 12 & $13[6-33]$ \\
\hline $\begin{array}{l}\text { Age at } \\
\text { regression, yo, } \\
\text { (median, } \\
\text { [interval]) }\end{array}$ & $3.5[2.5-7]$ & $2.7[2-3]$ & $1.3-2$ & 5.8 & $3[2-7]$ \\
\hline $\begin{array}{l}\text { DD prior to } \\
\text { regression }\end{array}$ & 3 & 0 & Mild speech delay & Yes & $5(33 \%)$ \\
\hline Microcephaly & $\begin{array}{l}6 \text { acquired ( } 1 \\
\text { borderline) }\end{array}$ & $\begin{array}{l}1 \text { acquired } \\
\text { (borderline) }\end{array}$ & NA & No & $7 / 12(58 \%)$ \\
\hline Ataxia & 3 & 4 & 1 (early on) & 1 (early on) & $9(67 \%)$ \\
\hline $\begin{array}{l}\text { Extrapyramidal } \\
\text { signs }\end{array}$ & $\begin{array}{l}6 \text { (3 dystonia, } 2 \\
\text { rigidity,1 chorea) }\end{array}$ & $\begin{array}{l}3 \text { ( } 3 \text { dystonia, } 1 \\
\text { chorea) }\end{array}$ & 1 (dystonic attacks) & $\begin{array}{l}1 \text { (dystonia, } \\
\text { chorea) }\end{array}$ & $11(85 \%)$ \\
\hline $\begin{array}{l}\text { Pyramidal } \\
\text { signs }\end{array}$ & 6 & 4 & Yes & Brisk DTR & $12(92 \%)$ \\
\hline $\begin{array}{l}\text { Behavioural } \\
\text { disorders }\end{array}$ & NA & $\begin{array}{l}4 \text { (hyperactivity, } \\
\text { impulsivity, 'autistic } \\
\text { behaviour') }\end{array}$ & $\begin{array}{l}\text { Apathy, social interaction } \\
\text { difficulties }\end{array}$ & $\begin{array}{l}\text { Apathy, agitation, } \\
\text { friendly }\end{array}$ & $6 / 6(100 \%)$ \\
\hline Dysarthria & NA & 4 & NA & Yes & $5 / 5(100 \%)$ \\
\hline $\begin{array}{l}\text { Swallowing } \\
\text { difficulties }\end{array}$ & NA & 3 & Yes (11yo) & Yes (11 yo) & $5 / 6(83 \%)$ \\
\hline $\begin{array}{l}\text { Seizures/ } \\
\text { Epilepsy }\end{array}$ & $\begin{array}{l}3 \text { (onset 5, } 14 \text { and } \\
15 y 0 \text { ) }\end{array}$ & 0 & Yes (multiple types) 6 yo & $\begin{array}{l}\text { Yes (behavioural } \\
\text { arrest) } 11 \text { yo }\end{array}$ & $5(38 \%)$ \\
\hline Outcome & $\begin{array}{l}7 \text { non verbal with } \\
\text { profound ID, } 6 \text { non } \\
\text { ambulatory }\end{array}$ & $\begin{array}{l}4 \text { language } \\
\text { regression, } 1 \text { non } \\
\text { ambulatory, } 1 \text { few } \\
\text { steps, } 4 \text { severe ID }\end{array}$ & $\begin{array}{l}\text { Non verbal, severe ID, non } \\
\text { ambulatory }\end{array}$ & $\begin{array}{l}\text { Non verbal, severe } \\
\text { ID, non } \\
\text { ambulatory }\end{array}$ & $\begin{array}{l}13 \text { non verbal or severe language } \\
\text { impairment and severe ID (100\%), } 9 \\
\text { non ambulatory (69\%), } 1 \text { limited } \\
\text { ambulation }\end{array}$ \\
\hline $\begin{array}{l}\text { EEG } \\
\text { abnormalities }\end{array}$ & 4 (no details) & $\begin{array}{l}\text { Abnormal } \\
\text { background rhythms }\end{array}$ & $\begin{array}{l}\text { Diffuse } \beta \text { activity (5yo), sharp } \\
\text { waves (6yo), continuous } \\
\text { bilateral FT spikes, slow } \\
\text { background. }\end{array}$ & Yes (see text) & 7 abnormal (53\%) \\
\hline Brain MRI & $\begin{array}{l}7 \text { cerebral atrophy } \\
\text { and T2 white } \\
\text { matter hs, } 5 \\
\text { cerebellar atrophy }\end{array}$ & $\begin{array}{l}4 \text { cerebral atrophy, } \\
\text { cerebellar atrophy } \\
\text { and white matter hs }\end{array}$ & $\begin{array}{l}\text { Cerebral atrophy, white } \\
\text { matter hs }\end{array}$ & $\begin{array}{l}\text { Cerebral atrophy, } \\
\text { mild cerebellar } \\
\text { atrophy, white } \\
\text { matter hs }\end{array}$ & $\begin{array}{l}13 \text { cerebral atrophy and white } \\
\text { matter hs }(100 \%), 10 \text { cerebellar } \\
\text { atrophy }(77 \%)\end{array}$ \\
\hline
\end{tabular}

yo years-old, $M$ male, $F$ female, $D D$ developmental delay, DTR deep tendon reflexes, ID intellectual disability, $F T$ frontotemporal, $h s$ hypersignal, $N A$ not available

any clinical correlate. Although abnormal EEG activity was reported in about half of the reported cases, only one other case was detailed [3]. In both, interictal epileptiform activity was characterized by anterior epileptiform discharges [3]. Generalized periodic epileptiform discharges with regression, suggests the diagnosis of subacute sclerosing panencephalitis secondary to measles or rubella [11]. However, in the latter case these complexes are more regular, faster (1$3 \mathrm{~Hz}$ ), sometimes intermingled with spikes and sharp waves, can occur during sleep [11-13] and translate into myoclonus. One can wonder whether this EEG pattern may be specific of c.628 C > G UBTF-associated neurodegeneration and whether it relates to a particular stage of the disease. Data analysis failed to reveal other variants that might have plausibly accounted for the EEG abnormalities, either under a recessive or a de novo dominant model [7]. Therefore, we suggest that this might be part of the c.628 $C>G$ $U B T F$ variant phenotype.

Even though UBTF c.628G>A -associated childhood neurodegeneration has a consistent phenotype, no pathognomonic clinical, imaging or biological features have been identified up until now, and diagnosis was in our case only achieved by NGS. Fever- or infection-triggered episodes of regression with negative metabolic work up and a periodic EEG pattern may be useful diagnostic cues that will have to be confirmed with further case studies. 


\section{Abbreviations}

CGH: Comparative Genomics Hybridisation; CSF: Cerebral-spinal fluid; DD: Developmental delay; DTR: Deep tendon reflexes;

EEG: Electroencephalogram; F: Female; FT: Frontotemporal; hs: Hypersignal; Hz: Hertz; ID: Intellectual disability; M: Male; MRI: Magnetic resonance imaging; NGS: Next Generation Sequencing; NA: Not available; (r)DNA: (ribosomal) Deoxyribonucleic acid; (r)RNA: (ribosomal) Ribonucleic acid; SW: Spike-wave; T2W: T2-weighted images; UBF: Upstream binding factor; UBTF: Upstream binding transcription factor; WES: Whole Exome Sequencing; yo: Years-old

\section{Acknowledgements}

Andrea O. Rossetti for his assistance in EEG readings.

\section{Author's contributions}

FB participated in the collection, analysis and interpretation of the clinical data and was a major contributor in writing the manuscript. MQ participated in the interpretation of the genetic testing and its relevance for this case. MCA participated in the interpretation of the genetic testing and its relevance for this case. BRB participated in the analysis of the genetic testing. HF participated in the analysis of the genetic testing. CR participated in the analysis of the genetic testing. HF participated in the analysis of the genetic testing. CP participated in the collection and interpretation of the clinical data. ASF participated in the interpretation of the genetic results, their relevance for this case and in the writing of the manuscript. ERP participated in the analysis, interpretation of the clinical data and in the writing of the manuscript. SL participated in the collection, analysis and interpretation and was a major contributor in writing the manuscript. All authors read and approved the final manuscript.

\section{Funding}

Filipa Bastos is supported by SICPA Foundation, Prilly, Switezerland.

\section{Availability of data and materials}

The data used and analysed during the current study are available from the corresponding author on reasonable request.

\section{Ethics approval and consent to participate}

This case report has been granted exemption from ethics approaval by the State of Vaud's Ethics Committee (CER-VD, Comission cantonale d'éthique de la recherche sur l'être humain, canton de Vaud), Lausanne, Switzerland.

\section{Consent for publication}

Informed verbal and written consent for the publication of this article was obtained from the parents of the patient.

\section{Competing interests}

The authors declare that they have no competing interests.

\begin{abstract}
Author details
'Department woman-mother-child, Unit of Paediatric Neurology and Neurorehabilitation, Lausanne University Hospital (CHUV), Rue du Bugnon 21, 1011 Lausanne, Switzerland. ${ }^{2}$ Great Ormond Street Hospital Institute of Child Health, University College London, 30 Guilford Steet, London WC1N 1EH, United Kingdom. ${ }^{3}$ Department of Computational Biology, Unit of Medical Genetics, University of Lausanne, Rue du Bugnon 27, 1011 Lausanne, Switzerland. ${ }^{4}$ Department of Medecine, Division of Genetic Medicine, Lausanne University Hospital (CHUV), Rue du Bugnon 46, 1011 Lausanne, Switzerland. ${ }^{5}$ Department of Genetics and Genome Biology, University of Leicester, University Road, Leicester LE1 7RH, United Kingdom. ${ }^{6}$ Department of Paediatrics, Sion Hospital, Avenue Grand-Champsec 80, 1950 Sion, Switzerland.
\end{abstract}

Received: 30 April 2019 Accepted: 22 December 2019

Published online: 13 January 2020

\section{References}

1. Edvardson S, Nicolae CM, Agrawal PB, Mignot C, Payne K, Prasad AN, et al. Heterozygous De Novo UBTF Gain-of-Function Variant Is Associated with Neurodegeneration in Childhood. Am J Hum Genet. 2017;101(2):267-73.
2. Toro C, Hori RT, Malicdan MCV, Tifft CJ, Goldstein A, Gahl WA, et al. A recurrent de novo missense mutation in UBTF causes developmental neuroregression. Hum Mol Genet. 2018;27(4):691-705.

3. Sedlackova L, Lassuthova P, Sterbova K, Haberlova J, Vyhnalkova E, Neupauerova J, et al. UBTF Mutation Causes Complex Phenotype of Neurodegeneration and Severe Epilepsy in Childhood. Neuropediatrics. 2018.

4. Katsuki J, Takashi H. RNA polymerase I transcription obstructs condensin association with 355 rRNA coding regions and can cause contraction of long repeat in Saccharomyces cerevisiae. Genes Cells. 2007;12(6):759-71.

5. Lam WW, Peterson EA, Yeung M, Lavoie BD. Condensin is required for chromosome arm cohesion during mitosis. Genes Dev. 2006;20(21):2973-84.

6. Royer-Bertrand B, Castillo-Taucher S, Moreno-Salinas R, Cho T-J, Chae J-H, Choi M, et al. Mutations in the heat-shock protein A9 (HSPA9) gene cause the EVEN-PLUS syndrome of congenital malformations and skeletal dysplasia. Sci Rep. 2015;5:17154.

7. Symonds JD, Zuberi SM, Stewart K, McLellan A, O'Regan M, MacLeod S, et al. Incidence and phenotypes of childhood-onset genetic epilepsies: a prospective population-based national cohort. Brain. 2019;142(8):2303-18.

8. Christensen CK, Walsh L. Movement Disorders and Neurometabolic Diseases. Semin Pediatr Neurol. 2018;25:82-91.

9. Hamilton EMC, van der Lei HDW, Vermeulen G, Gerver JAM, Lourenco CM, Naidu S, et al. Natural History of Vanishing White Matter. Ann Neurol. 2018; 84(2):274-88.

10. Sanij E, Diesch J, Lesmana A, Poortinga G, Hein N, Lidgerwood G, et al. A novel role for the Pol I transcription factor UBTF in maintaining genome stability through the regulation of highly transcribed Pol II genes. Genome Res. 2015;25(2):201-12.

11. GUTIERREZ J, ISSACSON RS, KOPPEL BS. Subacute sclerosing panencephalitis: an update. Dev Med Child Neurol. 2010;52(10):901-7.

12. Demir N, Cokar O, Bolukbasi F, Demirbilek V, Yapici Z, Yalcinkaya C, et al. A Close Look at EEG in Subacute Sclerosing Panencephalitis. J Clin Neurophysiol. 2013;30(4):348-56.

13. Ekmekci Ö, Karasoy H, Gökçay A, Ülkü A. Atypical EEG findings in subacute sclerosing panencephalitis. Clin Neurophysiol. 2005:116(8):1762-7.

\section{Publisher's Note}

Springer Nature remains neutral with regard to jurisdictional claims in published maps and institutional affiliations.

\section{Ready to submit your research? Choose BMC and benefit from:}

- fast, convenient online submission

- thorough peer review by experienced researchers in your field

- rapid publication on acceptance

- support for research data, including large and complex data types

- gold Open Access which fosters wider collaboration and increased citations

- maximum visibility for your research: over $100 \mathrm{M}$ website views per year

At $\mathrm{BMC}$, research is always in progress.

Learn more biomedcentral.com/submissions 